\title{
DESENVOLVIMENTO ÓSSEO E DENSITOMETRIA RADIOGRÁFICA EM CODORNA-JAPONESA (Coturnix japonica)
}

\section{BONE DEVELOPMENT AND RADIOGRAPHIC DENSITOMETRY IN JAPANESE-QUAIL (Coturnix japonica)}

\author{
Aline Luiza Konell ${ }^{1 *}$ \\ Thaiza Regina de Lima ${ }^{1}$ \\ Rafaella Martini ${ }^{1}$ \\ Rogério Ribas Lange ${ }^{1}$ \\ Sheron Sanches Sierakowiski ${ }^{1}$ \\ ${ }^{1}$ Universidade Federal do Paraná, Curitiba, PR, Brasil. \\ *Autora para correspondência - mvalinekonell@gmail.com
}

\section{Resumo}

O desenvolvimento ósseo nas aves é diferenciado e, radiograficamente, não existe uma placa de crescimento visível. A densitometria radiográfica (DR) é utilizada para avaliar e mensurar a densidade óssea. Foram utilizadas cinquenta e quatro codornas-japonesas (Coturnix japonica) de um dia de vida e de ambos os sexos. A cada três dias foram pesados dois animais e, em seguida, identificados, submetidos à eutanásia e radiografados. Foi utilizada uma escada de alumínio de vinte e um degraus para a mensuração densitométrica. Realizaram-se mensurações de comprimento do úmero, rádio, ulna, fêmur, tibiotarso e tarsometatarso; correlação do período de postura com a ocorrência de hiperostose poliostótica (HP) nos ossos longos; bem como avaliação densitométrica ao longo de 80 dias. Houve aumento na densidade óssea conforme crescimento em comprimento dos ossos em úmero, seguido pelo tibiotarso, ulna e fêmur, verificado principalmente no período de sete a 13 dias de vida. No úmero e no fêmur, houve significativo aumento de densidade óssea também entre 70 a 79 dias. A partir do $61^{\circ}$ dia, foi identificada a presença de hiperostose poliostótica nos fêmures das fêmeas. A DR é uma técnica aplicável em $C$. japonica como um método acessível e de baixo custo. Os resultados confirmam um grande aumento mineral ao longo do crescimento e durante a postura, confirmando a presença de HP na espécie.

Palavras-chave: ave; crescimento, densidade óssea; fise; radiografia.

\begin{abstract}
In birds, bone development is distinct and there is no radiographically obvious growth plate. Radiographic densitometry (RD) has been used to evaluate and measure bone density. Fifty-four one day-old Japanese quails (Coturnix japonica), of both sexes, were used. Every three days, two animals were weighed, identified, euthanized and x-rayed. A 21-step aluminum step wedge was used for densitometric measurements. The length of the humerus, radius, ulna, femur, tibiotarsus and tarsometatarsus was measured. Bone density increased as the bones grew in length in humerus followed by tibiotarsus, ulna and femur between 7 and 13 days of age. The humerus and femur
\end{abstract}


increased also between 70-79 days. From day 61 it was possible to identify polyostotic hyperostosis in female femurs. Radiographic densitometry is an accessible and low cost method applicable in $C$. japonica. The results confirm a large mineral deposition increasing during growth and also during the laying phase, confirming the presence of polyostotic hyperostosis in this specie.

Keywords: avian; bone density; bone growth; fisis; growth;

Recebido em: 29 de setembro de 2016

Aceito em: 18 de dezembro de 2017

\section{Introdução}

Codornas-japonesas (Coturnix japonica) são aves domésticas da ordem dos galináceos, família Fasianidae e gênero Coturnix ${ }^{(1)}$. A codorna ainda é um modelo animal experimental muito popular e é utilizada na produção de carne e ovos ${ }^{(2)}$.

Para auxiliar na redução do peso corpóreo, o sistema esquelético de grande parte das aves é caracterizado por um alto grau de pneumatização - primariamente envolvendo ossos como úmero, coracoide, esterno, cinturão pélvico e fêmur. $\mathrm{O}$ esqueleto é caracterizado por um córtex fino com padrão trabecular muito delicado. Os ossos longos contêm ar assim como, em menor grau, outras partes do esqueleto ${ }^{(3)}$.

O desenvolvimento ósseo em aves é diferenciado e, radiograficamente, não existe placa de crescimento visível como ocorre nos mamíferos. A ossificação e o crescimento ocorrem a partir de uma área cartilaginosa presente nas epífises. Com a persistência de partes cartilaginosas nas aves jovens, o esqueleto é pouco evidenciado radiograficamente ${ }^{(4)}$.

A radiografia é um dos exames complementares de maior utilidade no diagnóstico e prognóstico na clínica aviária. É um procedimento não invasivo, de baixo custo e facilmente acessível. As aves possuem sacos aéreos que favorecem a visualização radiográfica interna, e por circundarem os órgãos limitam a mobilidade destes. A radiografia é útil para o diagnóstico dos distúrbios musculoesqueléticos, assim como é importante na avaliação das doenças dos sistemas respiratório, gastrintestinal, cardiovascular e urogenital $^{(5)}$.

A cortical óssea é similar em ambos os sexos, mas, em fêmeas, a cavidade medular é muito instável e é onde reside a maior reserva de cálcio para a formação da casca do ovo ${ }^{(6)}$. O trabeculado ósseo é estabelecido no endósteo e, durante o período de postura, aumenta em $20 \%$ a quantidade de cálcio dos ossos longos - fenômeno chamado hiperostose poliostótica (HP), visível radiograficamente ${ }^{(7)}$. Esse fenômeno ocorre pelo aumento de estrógeno sérico (época reprodutivamente ativa das fêmeas), levando ao aumento de radiopacidade das cavidades medulares (principalmente em úmero, fêmur e tibiotarso). Essa intensificação de radiopacidade se dá pelo aumento da espessura do osso compacto e fixação do depósito de cálcio dentro da cavidade medular ${ }^{(3)}$, podendo também ocorrer em machos com tumores nas células de sertoli e em fêmeas com tumores ovarianos, e é necessária a diferenciação de casos fisiológicos ${ }^{(8)}$.

Nas imagens radiográficas típicas de ossos pneumáticos, visualiza-se um córtex radiopaco em torno de um sistema de pequenas trabéculas ósseas conectadas e, no exame radiográfico convencional, não é 
possível identificar alterações menores que $30 \%$ na mineralização ósseas ${ }^{(9)}$. A densitometria radiográfica (DR) é utilizada para mensurar a densidade óssea (DO), sendo a DR recurso útil no diagnóstico e orientação terapêutica em relação ao tratamento de doenças osteometabólicas, estudo de reparação óssea de fraturas e procedimentos cirúrgicos ${ }^{(10)}$. Devido aos altos custos para se adquirir aparelhos sofisticados para a realização de exames rotineiros de densidade óssea, a DR passa a ser uma opção barata, precisa e eficiente, sendo necessários poucos equipamentos para a realização de exames de rotina ${ }^{(11)}$.

Visto os diferentes períodos de ossificação das diferentes espécies de animais, o objetivo do trabalho foi determinar o desenvolvimento ósseo em ossos longos em codorna-japonesa, correlacionando com maturidade e densidade óssea, e verificar a presença de hiperostose poliostótica na espécie, bem como avaliar se há diferença densitométrica nos ossos das fêmeas em período de postura.

\section{Material e métodos}

O estudo foi aceito pela Comissão de Ética no Uso de Animais (CEUA) do Setor de Ciências Agrárias da Universidade Federal do Paraná (UFPR), Curitiba, Paraná, Brasil, sob protocolo número 065/2014.

Foram utilizadas 54 codornas-japonesas (Coturnix japonica), de um dia de vida e ambos os sexos, provenientes da Fazenda Experimental da UFPR. Do primeiro ao $14^{\circ}$ dia de vida os animais foram mantidos em duas gaiolas de alumínio de 50x50x50 cm de tamanho, sendo utilizado jornal como substrato e mantidos sob temperatura média de $28,7^{\circ} \mathrm{C}$. A partir do $15^{\circ}$ dia de vida os animais foram divididos em sete gaiolas aleatoriamente mantendo temperatura média de $25,3{ }^{\circ} \mathrm{C}$ com água e ração ad libitum, sendo ração de cria/recria até o $55^{\circ}$ dia e ração para postura até o $79^{\circ}$ dia de vida. O regime de luz foi estabelecido em 14 horas por dia, controlado por timer digital programável (FDD-60/SB2, G20, Santa Catarina).

Tabela 1. Quantidade de cálcio, fósforo e proteína bruta nas rações fornecidas às codornasjaponesas (Coturnix japonica) nas diferentes fases do crescimento

\begin{tabular}{cccc}
\hline Ração & Cálcio & Fósforo & Proteína bruta \\
\hline Cria/Recria & $9 \mathrm{~g} / \mathrm{Kg}$ & $3 \mathrm{~g} / \mathrm{Kg}$ & $22 \mathrm{~g} / \mathrm{Kg}$ \\
Postura & $37 \mathrm{~g} / \mathrm{Kg}$ & $6,2 \mathrm{~g} / \mathrm{kg}$ & $210 \mathrm{~g} / \mathrm{Kg}$ \\
\hline
\end{tabular}

A cada três dias, dois animais foram pesados em balança de $300 \mathrm{~g}$ Pesola® (Rebmattli 19, CH-6340 Baar, Switzerland), identificados, submetidos à eutanásia com injeção intramuscular de cetamina e xilazina (25 mg/kg e $1 \mathrm{mg} / \mathrm{kg}$, respectivamente) com posterior deslocamento cervical e radiografados. Os animais foram radiografados em posição ventrodorsal (VD) em aparelho digital (Agfa Healthcare CR-30-X, DS5302, Mortsel, Belgium) com técnica de 40 kVp, 100 mAs ${ }^{(12)}$ e distância aparelho-chassi de $35 \mathrm{~cm}$. Os corpos dos animais foram presos ao chassi com fita adesiva do tipo micropore no pescoço, asas e membros pélvicos (Fig. 1). Em todas as radiografias, utilizou-se uma escada de alumínio (penetrômetro) de 21 degraus com altura de $45 \mathrm{~mm}$ entre eles (diferentes espessuras de alumínio, liga 6063 ABNT) para posterior determinação da densitometria com o software ImageJ 1.48v (Wayne Rasband, National Institutes of Health, USA - Public Domain) (Fig. 2) e calibração para biometria, sendo este colocado sobre o chassi ao lado do animal. Mensurações de comprimento de úmero, rádio, ulna, fêmur, tibiotarso e tarsometatarso dos membros direito foram feitas em milímetros, utilizando o mesmo software. 


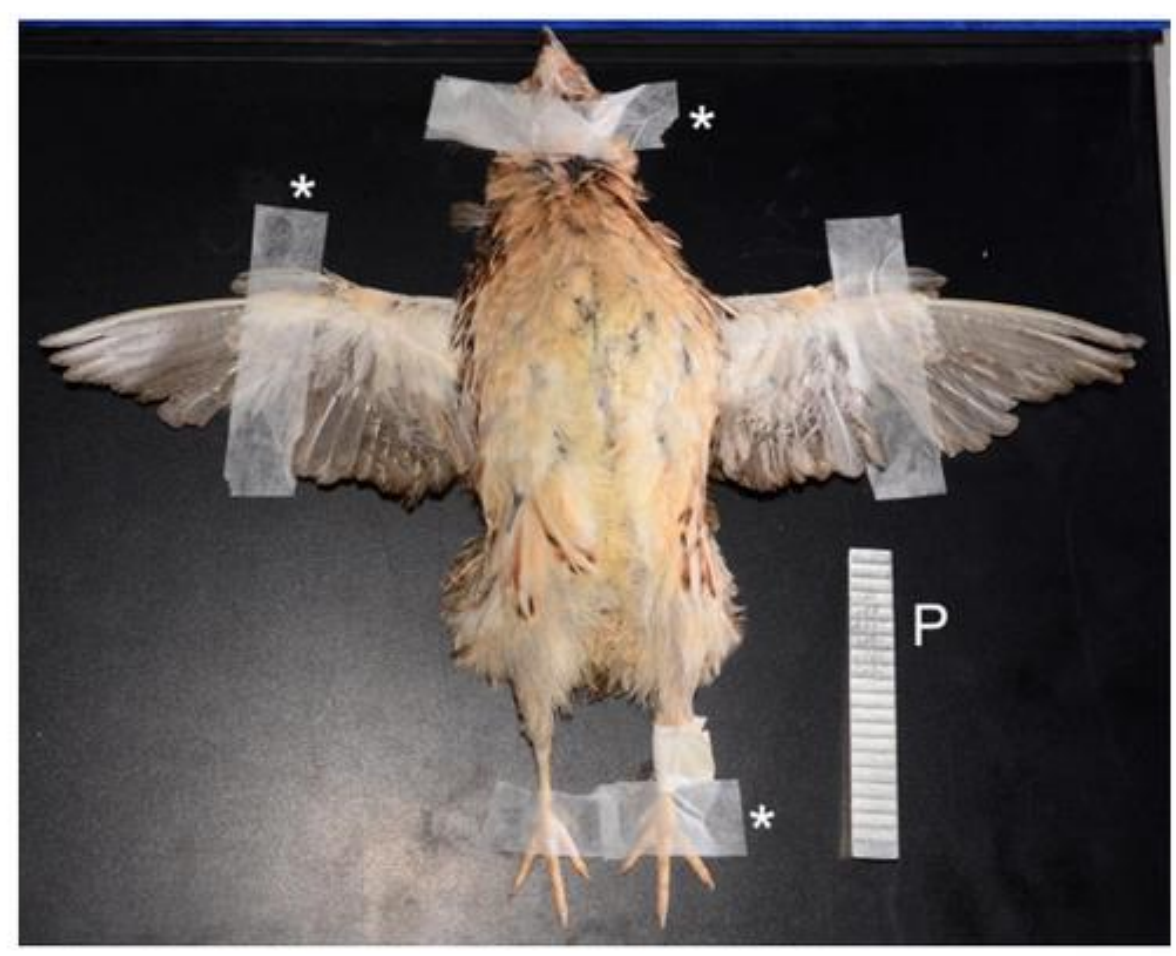

Figura 1. Coturnix japonica presa ao chassi para realização de radiografia. P: penetrômetro. Asteriscos marcam as áreas presas com micropore para correto posicionamento $e$ posterior interpretação (pescoço, asas e membros pélvicos).

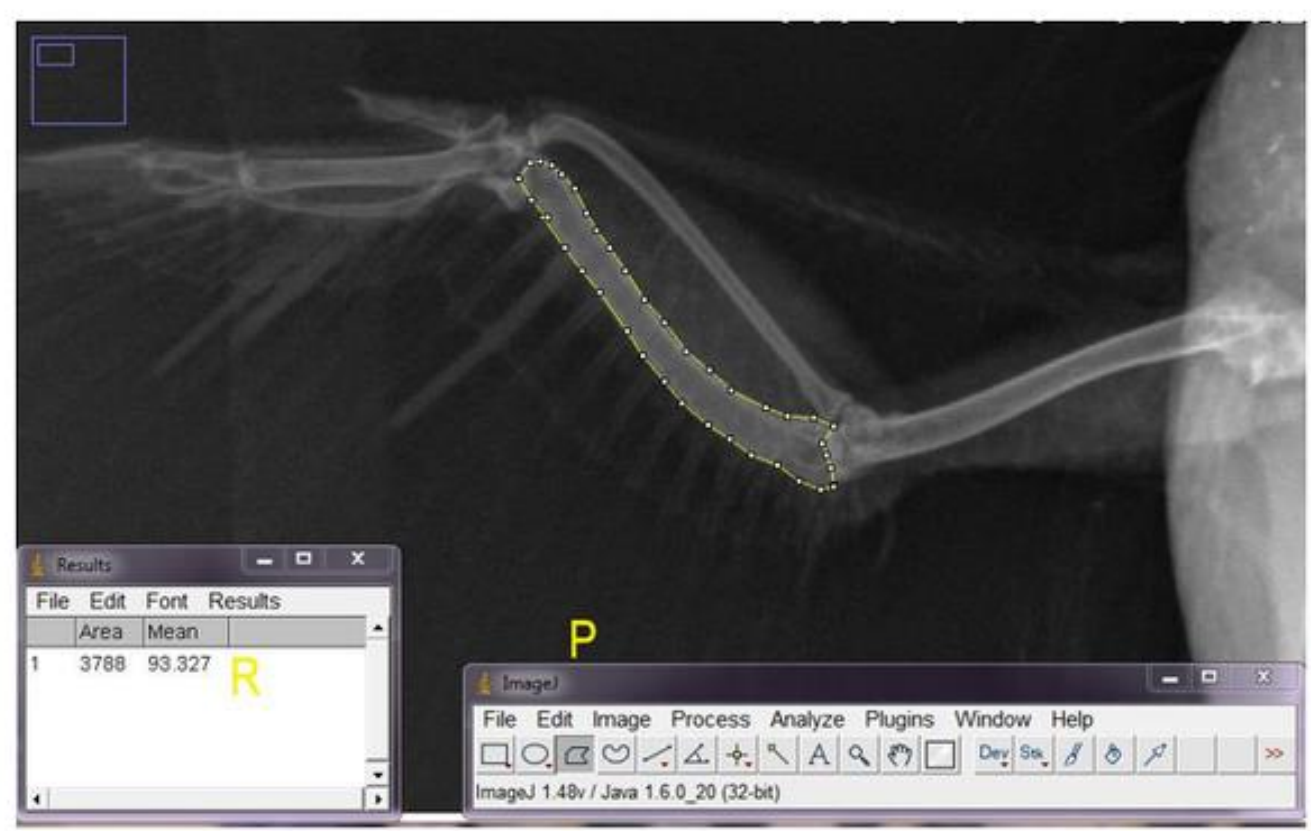

Figura 2. Interface do programa ImageJ com a radiografia de um animal de 43 dias. Pontilhado: área de interesse (ulna) selecionada para verificar a quantidade de tons de cinza presente na área. $\mathrm{P}$ : barra de ferramentas do programa. R: resultados calculados a partir da área total do osso de interesse (area) selecionada com a média (mean) de tons de cinza, utilizada para cálculo da densidade óssea.

Todas as radiografias foram analisadas individualmente pela mesma pessoa para avaliação de radiopacidade óssea, anormalidades, articulações, grau de ossificação epifisária e realização do cálculo da DR. As imagens foram processadas no programa ImageJ, no qual em cada radiografia o software era calibrado pela seleção dos 21 degraus de alumínio do penetrômetro para mensuração da 
quantidade de tons de cinza presentes em cada degrau. A região de interesse era delimitada em sua totalidade, em que se fornecia os tons de cinza presentes no osso. Tais resultados foram tabulados em planilha de Excel e, obtendo-se a quantidade de milímetros de alumínio presente na área de interesse, os cálculos foram realizados. Valores da DO de úmero, ulna, fêmur e tibiotarso direitos foram convertidos utilizando-se técnica de Louzada ${ }^{(13)}$ (Fig. 3).

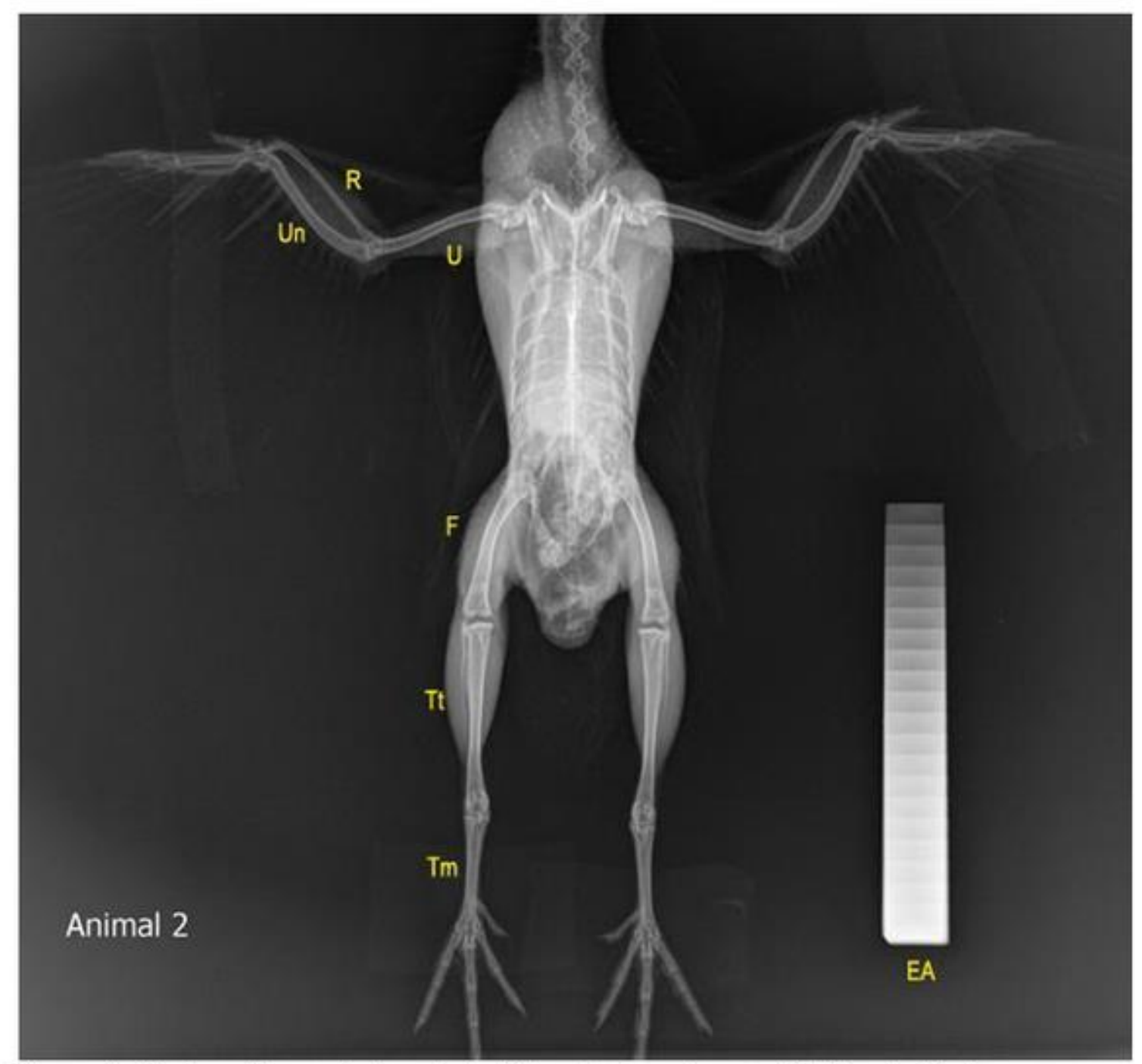

Figura 3. Radiografia ventrodorsal de Coturnix japonica aos 43 dias de idade, com a escada de alumínio (EA) de 21 degraus utilizada para a realização dos cálculos de densitometria. U: úmero, $R$ : rádio, Un: ulna, F: fêmur, Tt: tibiotarso, Tm: tarsometatarso.

$\mathrm{Na}$ asa, as mensurações foram feitas da seguinte forma: para o úmero, uma linha reta foi feita do meio da cabeça do úmero até próximo à fossa coronóidea. Para a ulna, uma linha paralela foi feita da diáfise do olécrano à diáfise da cabeça da ulna e, para o rádio, a linha foi feita da cabeça do rádio à diáfise do processo estiloide do rádio. Para o fêmur, uma linha foi traçada do meio da cabeça do fêmur ao côndilo medial. No tibiotarso, a linha foi traçada da epífise da área intercondilar anterior até o côndilo do tibiotarso e no tarsometatarso, a linha foi traçada da articulação intertarsiana até a articulação metatarsofalangeana.

Para realização da análise estatística, foram realizados os testes t, regressão linear e ANOVA two-way com o programa GraphPad Prism (GraphPad Software, Inc.). Para isso, os animais foram divididos aleatoriamente em grupos por idades: 1 a 19, 22 a 37, 40 a 58 e 61 a 79 dias de vida, e dentro desses 
grupos, por sexo.

\section{Resultados e discussão}

Do primeiro ao quarto dia de vida, não foi possível determinar o tamanho de úmero, rádio e ulna pela dificuldade em visualizá-los radiograficamente, devido à baixa radiopacidade dos ossos nesse período. No sétimo dia, somente o rádio não era delimitável. No décimo dia, a mudança de radiopacidade do esqueleto foi evidente, sendo possível a visualização da álula, ossos metacarpianos e fíbula. No dia 16, foi possível visualizar o início da fusão dos ossos tarsais. No $25^{\circ}$ dia, os carpos ulnares e radiais já estavam fusionados. Aos 28 dias, os ossos társicos apareceram fusionados e as patelas foram visualizadas e, no dia 37, a cabeça do úmero já pôde ser delimitada. Aos 40 dias, os ossos társicos já haviam se fusionado à tíbia, formando o tibiotarso e a segunda fileira de tarsos se apresentava fusionada ao metatarso, formando o tarsometatarso.

Em contraste aos mamíferos, as epífises de aves em crescimento não exibem zonas epifiseais de ossificação, com a exceção da junta intertarsal. Durante a maturação da junta intertarsal, cada um dos ossos tarsais se desenvolve separadamente, a primeira fileira de ossos tarsais se funde com a tíbia para formar o tibiotarso e o tarsometatarso se desenvolve da fusão dos ossos tarsais distais com o metatarso ${ }^{(14)}$. No $43^{\circ}$ dia, observou-se o fechamento dos dígitos e, entre o $52^{\circ}$ e $55^{\circ}$ dia, a articulação úmero-radioulnar estava completa. Apesar da grande diversidade de espécies aviárias, sendo mais de 1900 só no Brasil ${ }^{(15)}$, estudos a respeito de maturidade esquelética são escassos. Um estudo pioneiro foi realizado por Fowler ${ }^{(16)}$, quando se verificou que a maturidade esquelética em abutres se dá antes dos 60 dias de vida. Porém, tais animais, além de se tratarem de rapinantes, possuíam doença osteometabólica, condição que pode ter influenciado o estudo.

Aos 52 dias, foi possível visualizar estruturas arredondadas, compatíveis com folículos ovarianos nas fêmeas. Já nos machos, aos 58 dias verificou-se a presença de uma área bem delimitada, ovalada, com radiopacidade reduzida na região cloacal, condizente com as glândulas cloacais. Apesar de não ser o objetivo do trabalho, tais estruturas persistiram visíveis em todas as radiografias dos machos até o final do experimento. Foram também observados, no mesmo período, sinais de hiperemia e edema cloacal com a presença de espuma esbranquiçada nas gaiolas, peculiaridade do esperma desses animais.

A visualização do edema de cloaca e da presença de espuma é uma ferramenta não-invasiva de identificação da capacidade reprodutiva do macho ${ }^{(17)}$. Santos ${ }^{(18)}$ verificou que, a partir dos 55 dias, todas as células da linhagem espermática já se encontram na luz tubular, período compatível com os primeiros sinais de capacidade reprodutiva masculina visualizada em nosso experimento.

Aos 64 dias, as fêmeas iniciaram a postura de ovos. Em estudo realizado por Steigner e colaboradores ${ }^{(19)}$, com diferentes linhagens de codornas-japonesas, o primeiro dia de postura de uma linhagem pesada (semelhante à utilizada no presente trabalho) foi de 47,2 dias com uma média de peso de $218,1 \mathrm{~g}$. O peso das fêmeas no mesmo período foi semelhante (Fig. 4), porém, a postura tardia, se comparada ao trabalho de Steigner ${ }^{(19)}$, pode ser explicada por fatores como genética, alimentação, padrão de energia utilizado, temperatura ${ }^{(20)}$, fotoperíodo, tipo e intensidade de $l u z^{(21)}$. O início da postura observado no presente 
experimento também foi mais tardio que o relatado por Padgett e Ivey ${ }^{(22)}$, quando foi estabelecido que, em animais expostos a 14 horas de luz por dia, a maturidade sexual da fêmea ocorre entre a sexta e a sétima semanas de vida. A proximidade da fonte luminosa, a intensidade e o tipo da luz podem ter sido fatores que diferenciaram a maturidade sexual nos animais avaliados, que ocorreu na nona semana de vida.

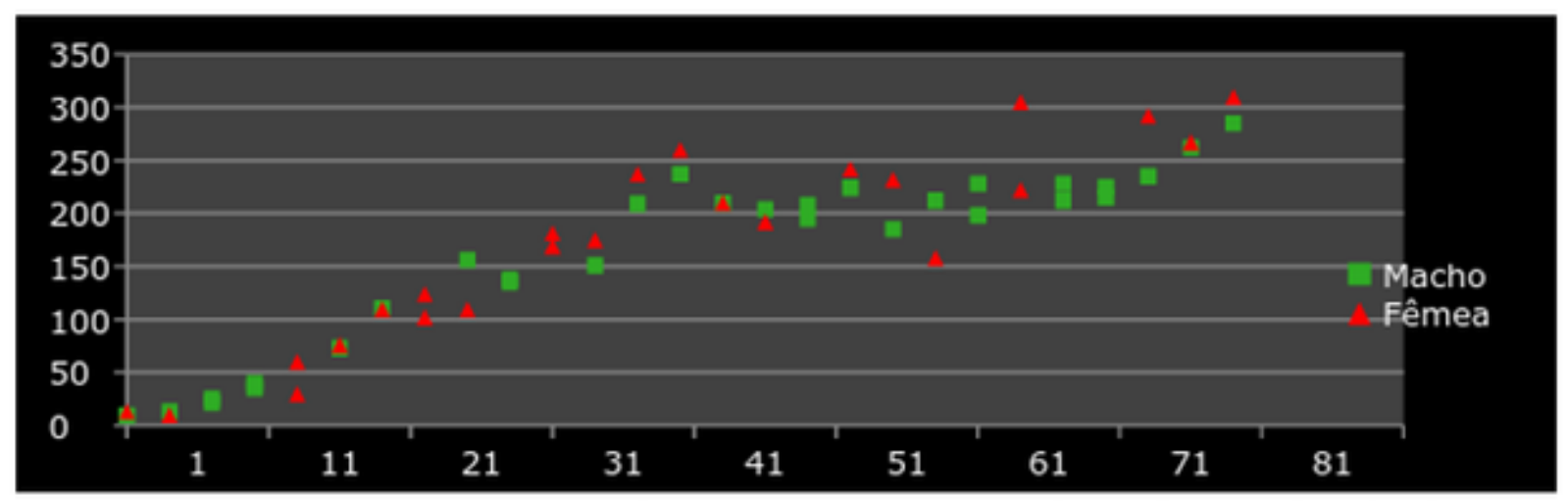

Figura 4. Massa corpórea em gramas de Coturnix japonica, machos e fêmeas, do primeiro ao $79^{\circ}$ dia de vida, mensurados com intervalos de três dias.

Entre 67 e 70 dias, houve o fechamento da articulação fêmoro-tibiotársica. Verificou-se que o posicionamento do animal (patas com extensão e angulação diferenciadas) influencia as imagens, já que, por não haver fises visíveis e padrão de distância articular em aves, a inspeção visual é subjetiva, dependendo da interpretação do observador.

O grau de alongamento e de desenvolvimento ósseo não são os mesmos em todas as partes dos ossos longos, sendo a ocorrência de alongamento maior na epífise e na área proximal, se comparada à diáfise. A região proximal e as epífises ósseas são responsáveis pelo desenvolvimento e alongamento, processo esse que ocorre por replicação condrocitária, maturação celular e mineralização ${ }^{(23,24)}$.

Neumann ${ }^{(25)}$ estabeleceu que não existe correlação entre a intensidade do crescimento e a taxa de desenvolvimento ósseo. Entretanto, outros autores afirmam que o desenvolvimento ósseo normal é influenciado pela alimentação, genética e aumento do peso vivo ${ }^{(26)}$. Buckner e colaboradores ${ }^{(27)}$ verificaram a relação entre o peso vivo e diversos aspectos do desenvolvimento de tibiotarso e fêmur em machos e fêmeas de frangos New Hampshire. Análises de seus dados demonstraram que mais de $98 \%$ da variabilidade do comprimento do tibiotarso e do fêmur foram em função do peso vivo.

Segundo Ricklefs ${ }^{(20)}$ e Santos $^{(18)}$, o peso dos machos se estabiliza a partir dos 60 dias de idade e o animal é considerado adulto com 70 dias. Notou-se que o peso vivo das fêmeas variou com maior frequência, o que pode ser explicado pela postura de ovos (Fig. 4). Em trabalho realizado por Ricklefs ${ }^{(20)}$, comparando diferentes padrões de desenvolvimento de aves (animais precoces, semiprecoces e altriciais), levantou-se a hipótese de que o aumento do peso corporal e a taxa de crescimento são inversamente relacionados ao grau de maturidade funcional. A taxa de crescimento das diferentes espécies está relacionada ao peso vivo do adulto, disponibilidade de alimento, período que o animal permanece no ninho e padrão de desenvolvimento (precoce, semiprecoce ou altricial). Rapinantes (altriciais) por exemplo, crescem muito mais rápido que galiformes (como a codorna - animal precoce) de mesmo peso. A energia utilizada por aves precoces para manter sua atividade e regulação de temperatura pode limitar a energia disponível para o crescimento. Ricklefs ${ }^{(20)}$ ainda sugere que o desenvolvimento dos membros pélvicos determina a taxa de crescimento da codorna-japonesa e pode definir o ritmo do desenvolvimento das aves. 
Em relação às densidades ósseas, em análise de regressão linear, comparando a DO do úmero, da ulna, do fêmur e do tibiotarso com os seus respectivos comprimentos em milímetros, houve significância ( $\mathrm{p}<0,05$ ), ou seja, a densidade óssea aumentou conforme os ossos aumentaram em comprimento. O maior coeficiente de correlação $(0,81)$ ocorreu no úmero, demonstrando que o crescimento do úmero está intimamente ligado ao aumento da DO, seguido pelo tibiotarso $(0,756)$, ulna $(0,71)$ e fêmur $(0,628)$ (Fig. $5)$.

Em todos os ossos estudados (úmero, ulna, fêmur e tibiotarso), o período entre o sétimo e o $13^{\circ}$ dia diferiu das demais idades $(\mathrm{p}<0,05)$, podendo haver nesta fase do crescimento maior mobilização de cálcio para osteogênese. No úmero e no fêmur, também houve diferença no período de 70 a 79 dias, fase que coincide com o início da postura nas fêmeas (aos 64 dias). A hiperostose poliostótica (HP) (também chamada de osso medular) é uma característica fisiológica observada em fêmeas antes da postura e trata-se de um sítio fisiológico de armazenamento de cálcio ${ }^{(28)}$. Logo, a densidade óssea aumenta pelo acúmulo mineral. Outro fator a ser considerado é a presença de grandes massas musculares ao redor dos ossos longos dos membros pélvicos. Camargo Filho ${ }^{(11)}$ escolheu a ulna como osso padrão para avaliação da DO por possuir boa espessura e apresentar menor sobreposição de tecidos moles e penas, reduzindo assim a influência nos resultados. Um dos pontos a se questionar na maior densidade femoral (bem como alta densidade em tibiotarso - mesmo não apresentando diferença estatística) é a presença de grandes massas musculares. A somatória da musculatura e do tecido ósseo culmina com a leitura de uma maior DO pela sobreposição. Deve-se ressaltar que a adição das densidades óssea e muscular pode ter sido responsável pelos resultados obtidos em fêmur e tibiotarso.

No período de 61 a 79 dias, realizou-se a comparação da DO dos fêmures de machos e fêmeas para analisar a presença de HP nas fêmeas (Fig. 6). A presença de HP nas fêmeas foi confirmada ( $<<0,05)$, condizendo com a época reprodutiva dos animais, quando as fêmeas acumulam cálcio nos ossos longos para a formação da casca dos ovos.
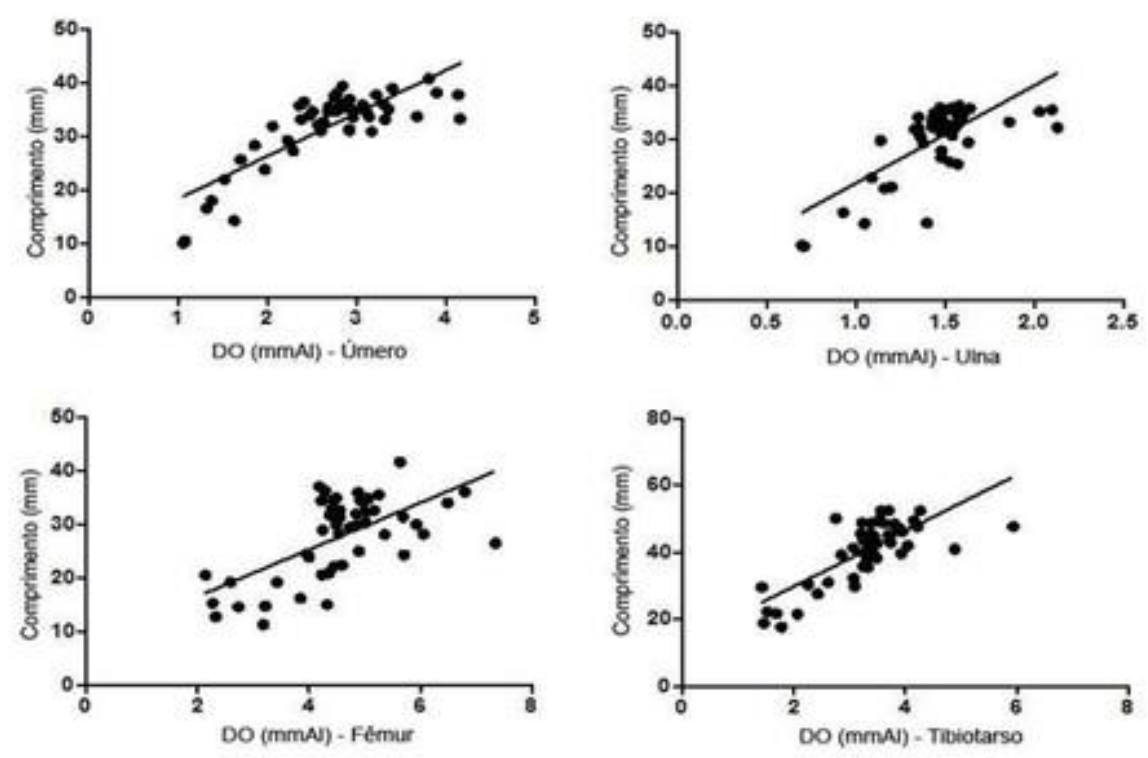

Figura 5. Densidade óssea de ossos longos de codornas-japonesas ao longo de 79 dias de vida. Regressão linear positiva da DO de ulna, úmero, fêmur e tibiotarso. 


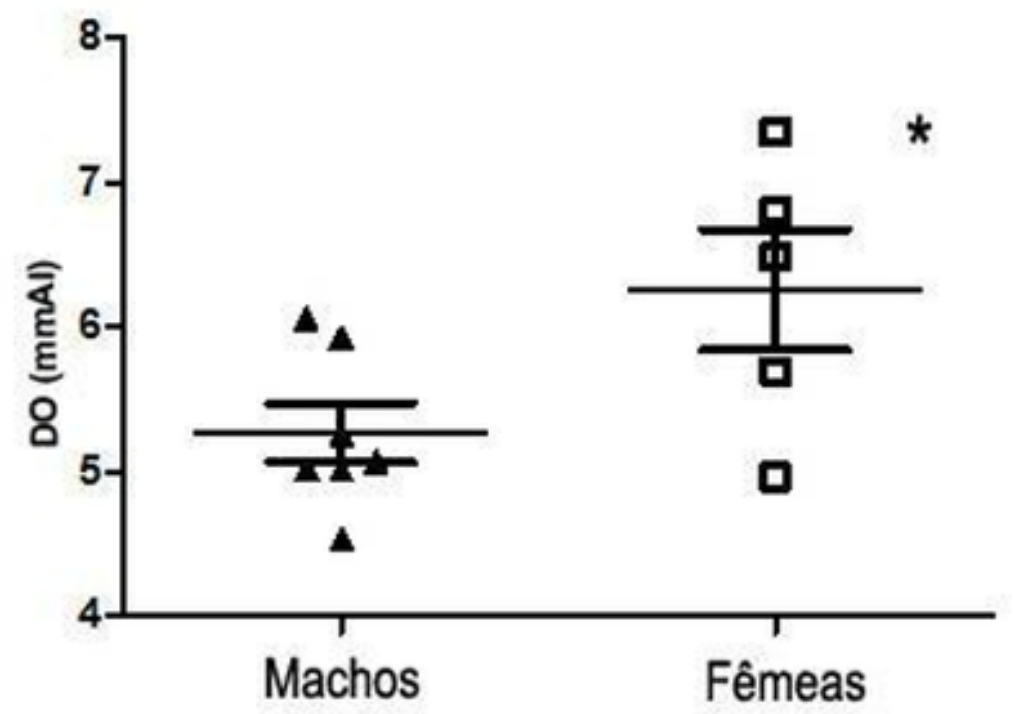

Figura 6. Densidade óssea de fêmures de codorna-japonesa (Coturnix japonica) de 61 a 79 dias de vida. ${ }^{*} \mathrm{p}<0,05$.

\section{Conclusão}

A DR é uma técnica aplicável a $C$. japonica, sendo um método acessível e de baixo custo que permite o estabelecimento de diversos padrões osteológicos e ortopédicos. Os resultados observados confirmaram um grande aumento de densidade ao longo do crescimento animal, bem como durante a postura, confirmando a presença de hiperostose poliostótica na espécie. Verificou-se, também, radiograficamente, a presença das glândulas cloacais no macho adulto, outra forma de comprovar o sexo desses animais.

\section{Agradecimentos}

Prof. Dr. Mario Jefferson Quirino Louzada pela ajuda com os cálculos de DO.

\section{Referências}

1. Murakami AE, Ariki J. Produção de codornas japonesas. Jaboticabal: Funep; 1998. 79p.

2. Ainsworth, Sophie J and Stanley, Rachael L and Evans, Darrell JR. Developmental stages of the Japanese quail. Journal of Anatomy. 2010; 216(1): 3-15.

3. Demiraslan Y, Tufan T, Sari M, Akbulut Y, Dayan MO, Kukurt A. The effect of clinoptilolite on long bone morphometry in japanese quail (Coturnix coturnix japonica). Animal and Veterinary Sciences. 2014; 2(6): 179-183.

4. Krautwald-Junghanns ME, Pees M. Técnicas de diagnóstico por imagem. In: Tully T, Dorrestein GM, Jones 
AK. Clínica de aves. São Paulo: Elsevier; 2010. p. 75-85.

5. Cubas, ZS, Godoy SN. Medicina e patologia de aves de companhia. In: Aguilar R, Hernández-Divers SM, Hernández-Divers SJ. Atlas de medicina, terapêutica e patologia de animais exóticos. São Caetano do Sul: Interbook; 2006. p. 213-264.

6. Tully TN. Basic avian bone growth and healing. In: Tully TN. The veterinary clinics of north america: exotic animal practice. Vol. 5. Orthopedics. Philadelphia: WB Saunders; 2002. p. 23-31.

7. O’Malley B. Avian anatomy and physiology. In. O’Malley B. Clinical anatomy and physiology of exotic species. Philadelphia: Elsevier; 2005. p. 97-101.

8. Macwhirter P. Evolução das espécies aviárias. In: Tully T, Dorrestein GM, Jones AK. Clínica de aves. São Paulo: Elsevier; 2010. p. 1-21.

9. Garton MJ, Robertson EM, Gilbert FJ, Gomerssal L, Reid DM. Can radiologists detect osteopenia on plain radiographs? Clinical radiology. 1994; 49(2): 118-122.

10. Louzada MJQ, Nogueira GP, Garcia Junior IR, Carvalho CA, De Paula GA. Densitometria óptica radiográfica em análise de densidade óssea de mandíbula de coelhos castrados. Revista da Faculdade de Odontologia de Lins. 2001; 13(1): 33-38.

11. Camargo Filho OB. Influência de diferentes dietas na densidade óssea de calopsitas (Nymphicus hollandicus). Veterinária e Zootecnia. 2014; 21(3): 409-420.

12. Harcourt-Brown N. Diagnostic imaging. In: Harcourt-Brown N, Chitty J. BSAVA Manual of Psittacine Birds. England: BSAVA; 2005. p. 97-106.

13. Louzada, MJQ, Pelá CA, Belangero WD, Santos-Pinto R. Metodologia para avaliação de densidade em imagem radiográfica. RBE - Caderno de Engenharia Biomédica. 1998; 14(2): 37-47.

14. Krautwald-Junghanns ME, Schroff S, Bartels T. In: Krautwald-Junghanns ME, Pees M, Reese S, Tully T. Diagnostic imaging of exotic pets. Germany: Schlutersche; 2011. p. 1-35.

15. Piacentini VDQ, et al. Annotated checklist of the birds of Brazil by the Brazilian Ornithological Records Committee / Lista comentada das aves do Brasil pelo Comitê Brasileiro de Registros Ornitológicos. Revista Brasileira de Ornitologia. 2015; 23(2): 91-298.

16. Fowler ME. Ossification of long bones in raptors. In: Cooper JE, Greenwood AG. Recent advances in the study of raptor diseases. London: Chiron Publications; 1981. p.75-82.

17. Biswas A, Ranganatha JM, Sastry KVH. Relationship of cloacal gland with testes, testosterone and fertility in different lines of male Japanese quail. Animal Reproduction Science. 2007; 97(1): 94-102.

18. Santos TC, Murakami AE, Oliveira CAL, Costa PD. Body and testicular development in males of meat and egg-type quails of 25 to 360 days. Pesquisa Veterinária Brasileira. 2012; 32(11): 1205-1212.

19. Steigner JW, Nestor KE, Lilburn MS. Growth and development of lines of japanese quail (Coturnix coturnix japonica) divergently selected for body weight at 4 weeks of age. Comparative Biochemistry Physiology. 1991; 10(2): 389-392.

20. Ricklefs RE. Patterns of growth in birds. V. A comparative study of development in the starlings, common tern and japanese quail. The Auk. 1979; 96: 10-30.

21. Hosick HL. The influence of light intensity on oviposition of the coturnix quail. Wilson Bulletin. 1966; 78(4): 434-443.

22. Padgett CA, Ivey WD. Coturnix quail as a laboratory research animal. Science. 1959; 129(3344): 267268. 
23. Applegate TJ, Lilburns MS. Growth of the femur and tibia of a commercial broiler line. Poultry Science. 2002; 81: 1289-1294.

24. Dibner JJ; Richards JD, Kitchell ML, Quiroz MA. Metabolic challenges and early bone development. The Journal of Applied Poultry Research. 2007; $16:$ 126-137.

25. Neumann J. Changes in bone tissue of broilers treated with growth promoters. Acta Veterinaria Brno. 1986; $55(4): 285-291$.

26. Kocabagli N. The effect of dietary phytase supplementation at different levels on tibial bone characteristics and strength in broilers. Turkish Journal of Veterinary and Animal Sciences. 2001; 25(5): 797-802.

27. Buckner GDW, Insko JRM, Harms-Henry A, Faull-Wachs E. The comparative rates of growth and calcification of the femur, tibia and metatarsus bones of the male and female New Hampshire chicken having straight keel. Poultry Science. 1950; 29(3):332-335.

28. Pees M. Radiography. In: Chitty J, Lierz M. BSAVA Manual of raptors, pigeons and passerine birds. BSAVA England: BSAVA; 2008. p.114-120. 